\title{
Use of Non-Pathogenic Biological Agents as Biological Warfare Simulants for the Development of a Stand-Off Detection System
}

Orlando Cenciarelli ${ }^{1,2 *}$, Stefano Pietropaoli ${ }^{3 \dagger}$, Valentina Gabbarini ${ }^{4 \dagger}$, Mariachiara Carestia ${ }^{1,2}$, Fabrizio D'Amico $^{1,2}$, Andrea Malizia $^{1,2}$, Michela Gelfusa ${ }^{1}$, Roberto Pizzoferrato ${ }^{1}$, Alessandro Sassolini ${ }^{1,4}$, Daniele Di Giovanni ${ }^{1,2}$, Francesca Maria Orecchio ${ }^{4}$, Leonardo Palombi2,5, Carlo Bellecci ${ }^{1,2}$, and Pasqualino Gaudio ${ }^{1,2}$

${ }^{1}$ Department of Industrial Engineering, University of Rome Tor Vergata, Italy

${ }^{2}$ Scientific Board of International Master courses in "Protection against CBRNe events", University of Rome Tor Vergata, Italy

${ }^{3}$ Department of Science, University of Rome 3, Italy

4International Master courses in "Protection against CBRNe events", University of Rome Tor Vergata, Italy

${ }^{5}$ Department of Bio-Medicine \& Prevention, University of Rome Tor Vergata, Italy

${ }^{t}$ these authors contributed equally to the manuscript

\begin{abstract}
Development of new technologies for Biological Warfare Agents (BWA) stand-off detection implies several safeties, logistic and economic drawbacks that involve production of different highly virulent bacteria and viruses, their isolation and characterization under adequate bio-containment and sample preparation for each agent to evaluate the testing method. In order to overcome these difficulties most of the research activities and tests reported so far, are performed using simulants: Biological Agents (BA) which are phylogenetically or structurally related to BWA. The use of the simulants (BWA-S) show, however, some limitations: they can share some of the properties of the biological warfare agents but have different antigens, proteome and genome. In this work, different BWA-S was evaluated for the application in the development and training of stand-off detection systems. This study is the basis for the use of simulants in the development of an Ultraviolet Laser Induced Fluorescence (UV-LIF) based detection systems.
\end{abstract}

Keywords: Bioweapons; Stand-off detection; Bio-detection; Biological agents; Simulants

\section{Introduction}

The 2001 anthrax attacks in USA spread the fear of a bioterrorist attack worldwide. Since then, letters with suspicious powder are a regular phenomenon all over the world [1]. The real threat of a largescale biological attack gets the defense against bioweapons not only a national security issue but also a public health priority [2]. The hypothetical use of Biological Warfare Agents (BWAs) represents a severe concern in both military and civilian frameworks, since the lack of quick and effective tools for warning and detection of a biological attack could cause a high-potential impact $[3,4]$.

Comparing with other non-conventional offensive agents, as chemical or radiological weapons, BWAs show a high lethality and the ability (with the exception of toxins) to multiply in the host and to spread among the population. After their release, some BWAs can remain viable in the environment for a significant period, determining a continuous risk [5]. Therefore, the control of biological threats is extremely difficult. In addition, if compared with other nonconventional weapons, BWAs have a paltry production cost. Several biological agents can be used as weapons; for this reason and for the different dissemination ways into the environment and among people, biodefense is extremely complex [6].

Stand-off detection and warning of BWA release represent the main goal to be achieved in order to reduce the biological threat and the risk for population [7]. In contrast to the point detection systems, which requires close proximity to the samples that need to be analyzed, the stand-off detection systems allows to analyze samples remotely, thus making possible an early identification of the contamination source. Preliminary studies carried out using UV-LIF technique show promising results for the detection and discrimination of biological particles [8], thanks to the presence of endogenous fluorophores (the amino acids Tryptophan and Tyrosine, the cofactor Nicotinamide
Adenine Dinucleotide-NADH, riboflavines, dipicolinic acid), which are able to emit fluorescence when excited at specific wavelengths in the UV range. Many projects were carried out with the main aim to perform stand-off revelation of biological agents through optical techniques (e.g. photoluminescence), but limited attention was paid on biosimulants [3].

To date, several technologies for the detection of biological agents, based on photoluminescence, were developed, for the most part capable of point detection $[9,10]$. Therefore, it is of primary importance to develop tools for the detection biological agents released at a distance, distinguishing from the environmental background [11]. The use of non-pathogenic microorganisms or molecules as simulants of Biological Warfare Agents (BWA-S) is essential in the initial phase of detection methodologies development. In this paper three main categories of BWA-S were analyzed: 1) Bovine Serum Albumin (BSA) and Ovalbumin (OVA), which simulate protein toxins; 2) Bacillus subtilis (BS) and Bacillus thuringensis (BT) spores, which simulate hazardous bacterial spores (e.g. Bacillus anthracis spores); 3) Escherichia coli and the vegetative form of Bacillus subtilis which simulate Gram-negative and Gram-positive bacteria, respectively. Simulants of viruses (i.e. variola virus or Viral Hemorrhagic Fevers

*Corresponding author: Orlando Cenciarelli, Department of Industrial Engineering, University of Rome Tor Vergata, Via del Politecnico 1-00133 Rome, Italy, Tel: +390672597198; E-mail: orlando.cenciarelli@uniroma2.it

Received November 02, 2014; Accepted November 16, 2014; Published November 24, 2014

Citation: Cenciarelli O, Pietropaoli S, Gabbarini V, Carestia M, D'Amico F, et al. (2014) Use of Non-Pathogenic Biological Agents as Biological Warfare Simulants for the Development of a Stand-Off Detection System. J Microb Biochem Technol 6: 375-380. doi:10.4172/1948-5948.1000172

Copyright: (c) 2014 Cenciarelli O, et al. This is an open-access article distributed under the terms of the Creative Commons Attribution License, which permits unrestricted use, distribution, and reproduction in any medium, provided the original author and source are credited 
(VHF) agents), although important, were not discussed in this paper. Before investigating the preparation of different samples, in fact, that require different techniques of culture and preparation, a preliminary analysis of some easily obtainable spectra was considered useful to the adaptation and the training of the neural network.

\section{BWA Simulants for the Development of Stand-Off Detection Systems}

A large number of pathogens causes diseases in humans, however only few of them have the features to be used as bioweapons $[4,6,12]$. Offensive use of biological agents, or their toxins, is prohibited by several international conventions, which do not seem, however, to have tarnished the war policy of many states that publicly, or more often in secrecy, continue to study and produce BWA [13-15].

To be effective as bioweapon, a biological agent should possess several features, including high lethality, communicability, fast and predictable action, ability to survive in the environment as long as it encounters its host and resistance to destruction with air, water and food purification methods. In addition, a suitable biological agent should be susceptible to treatments or vaccines which are only available to who perform the attack and not accessible to the victims [16]. Moreover, to be used as a weapon, biological agents should be produced on a large scale, able to disseminate itself in efficient manner and to produce a strong public impact [17]. Modern bioengineering and molecular biology techniques can potentially allow achieving these objectives, for example creating antibiotic-resistant strains of anthrax, reducing the time of incubation of smallpox or combining agents such as Ebolavirus and anthrax in order to develop new diseases. Furthermore, it is believed that the interest of some organizations is turning on genetically altering agents $[18,19]$.

Among a large number of pathogenic biological agents, the American Centers for Diseases Control and Prevention (CDC), [20] together with military, intelligence, medical and public health agencies, classifies the most important bioterrorism agents into three categories (Table 1):

a) Category A: agents that can be easily disseminated or transmitted from person to person. They result in high mortality rates and have the potential for major public health impact. They might cause public panic and social disruption, and require special action for public health preparedness.

b) Category B: agents that is moderately easy to disseminate. They result in moderate morbidity rates and low mortality, and require specific enhanced diagnostic capacity and disease surveillance.

c) Category C: emerging agents that could be engineered for mass dissemination in the future because of their availability. They are easy to produce and disseminate. They are potentially linked to high morbidity and mortality rates, and major health impact.

In every research addressed to develop new stand-off revelation systems, the employment of pathogens included in the previously mentioned Category $\mathrm{A}$ as B. anthracis, C. botulinum, Y. pestis and $F$. tularensis and other harmful bacteria is an extremely hazardous operation. To solve the problems connected to isolation, characterization and preparation of these pathogens, researchers resort to simulants (BWA-S). A BWA-S is a harmless biological agent which mimics the physical and structural properties of a real BWA without causing any adverse health effects. However, it is important to consider that the use of the simulants show some critical points. In fact, if on one hand they are related to BWA and share many of their morphological characteristics, on the other hand, they are genetically and immunologically different.

\section{Bacterial BWA and BWA-S}

Fermentation, decomposition of organic substances, and

\begin{tabular}{|c|c|c|c|c|}
\hline Category & Origin & Agents & Main Characteristics & Diseases \\
\hline \multirow{7}{*}{ A } & \multirow{4}{*}{ Bacterial } & Bacillus anthracis & Gram +; spore forming & Anthrax \\
\hline & & Clostridium botulinum toxins & Gram +; spore forming; toxins & Botulism \\
\hline & & Yersinia pestis & Gram - & Plague \\
\hline & & Francisella tularensis & Gram - & Tularemia \\
\hline & \multirow{3}{*}{ Viral } & Variola major & dsDNA genome; & Smallpox \\
\hline & & Filoviruses & ss(-)RNA genome & Viral hemorrhagic fevers \\
\hline & & Arenaviruses & segmented ss(-)RNA genome & \\
\hline \multirow{15}{*}{ B } & \multirow{12}{*}{ Bacterial } & Brucella spp. & Gram - & Brucellosis \\
\hline & & Clostridium perfringens & Gram +; spore forming; toxins & Epsilon toxin \\
\hline & & Salmonella spp. & Gram - & Food safety threats \\
\hline & & E. coli $\mathrm{O} 157: \mathrm{H} 7$ & Gram - & \\
\hline & & Shigella & Gram - & \\
\hline & & Vibrio cholerae & Gram - & Water safety threats \\
\hline & & Burkholderia mallei & Gram - & Glanders \\
\hline & & Burkholderia pseudomallei & Gram - & Melioidosis \\
\hline & & Coxiella burnetii & Gram - & $Q$ fever \\
\hline & & Chlamydia psittaci & Gram - & Psittacosis \\
\hline & & Staphylococcus spp. & Gram +; toxins & $\begin{array}{c}\text { Food poisoning by Staphylococcal } \\
\text { enterotoxin B }\end{array}$ \\
\hline & & Rickettsia prowazekii & Gram - & Typhus fever \\
\hline & Protozoa & Cryptosporidium parvum & sporulated oocysts production & Water safety threats \\
\hline & Viral & Alphaviruses & ss(+)RNA genome & Viral encephalitis \\
\hline & Plant & Ricinus communis & Toxins & Ricin poisoning by ricin toxin \\
\hline \multirow{2}{*}{ C } & \multirow{2}{*}{ Viral } & Nipahvirus & ss(-)RNA genome & \multirow{2}{*}{ Emerging infectious diseases } \\
\hline & & Hantavirus & ss(-)RNA genome & \\
\hline
\end{tabular}

Table 1: Biological agents suitable as bioweapons [20]. Main characteristics and the caused diseases are also reported. 
production of antibiotics or vaccines useful for health are some of the many processes performed by bacteria, which make them essential for the whole biosphere balance. However, their potential use as bioweapons represents a real concern of the modern society, involving scientific world and public opinion. Both Gram-negative and Gram-positive bacteria species have been used in the past or can be potentially used in future for bioterrorist purposes. The differences in the morphology of the Gram-positive and Gram-negative bacteria are summarized in Figure 1. Gram-negative pathogens that could be weaponized by terrorists include, among other, $Y$. pestis and $F$. tularensis. $Y$. pestis, the etiological agent of plague, is a rod-shaped coccobacillus, belonging to the family of Enterobacteriaceae [21]. The disease may occur in three different forms: -pneumonic, septicemic, and bubonic plague and can spread through vectors (e.g. infected flies) or aerosol. Symptoms persist for 1 to 6 days, and usually led to a fatal outcome; lethality rate is low (5-10\%) after treatment, while it increases in untreated patients ranging from $30-75 \%$ for bubonic plague to $95 \%$ for pneumonic form. Due to its high transmissibility rate, tests with $Y$. pestis represent a serious risk for operators, resulting in the need for non-pathogenic biological agents to be used for its detection. $F$. tularensis is a non-motile, non-spore-forming, strict aerobe bacterium. It is the etiological agent of tularemia, whose pneumonic form is often lethal if untreated [22]. F. tularensis is a very virulent and dangerous pathogen, owing to its low infective dose that implies high virulence, and the possibility to be easily disseminated by aerosol. Species of Enterobacteriaceae family may be used as potential Gram-negative bacteria simulants, in order to reduce the riskiness connected to the use of the real bioterrorist threats. Among these, Pantoea agglomerans, also known as Erwinia herbicola, is considered an appropriate simulant. E. herbicola is a rod-shaped, non-pathogenic, Gram-negative facultative anaerobe, widespread in nature as an epiphyte on many plants [23]. However, the use of E. herbicola as a simulant is limited by two main factors: firstly, its antigenicity is not appropriate as a backup for other detection methods used; secondly, its low resistance when aerosolized makes this organism not suitable aerosolized to mimic an airborne bioweapon [24]. E. herbicola disadvantages for being a good simulant have moved the attention on non-pathogenic strains of E. coli, a Gramnegative, facultative anaerobic, rod-shaped and non-spore forming bacterium. Nevertheless, E. coli cells can survive for only a brief period outside the host.

Gram-positive bacteria that may be used in bioterrorist actions are, among other, B. anthracis and C. botulinum [4]. Peculiarity of Gram-positive bacteria is the spores production (see next section). The

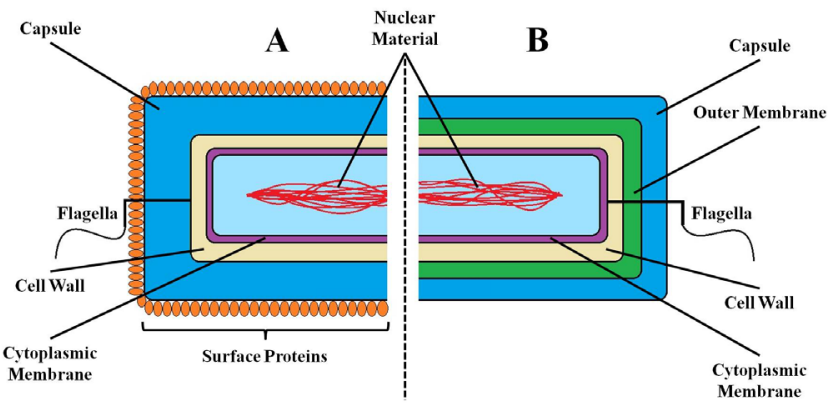

Figure 1: (A) Gram-positive and (B) Gram-negative bacteria. Gram-positive (A) bacteria show from the outer to the inner: a) surface proteins; b) capsule; $c$ ) cell wall; d) cytoplasmic membrane; e) cytoplasm with nuclear material intersperse. Gram-negative (B) bacteria show from the outer to the inner: a) capsule; b) outer membrane; c) cell wall; d) cytoplasmic membrane; e) cytoplasm with nuclear material intersperse.

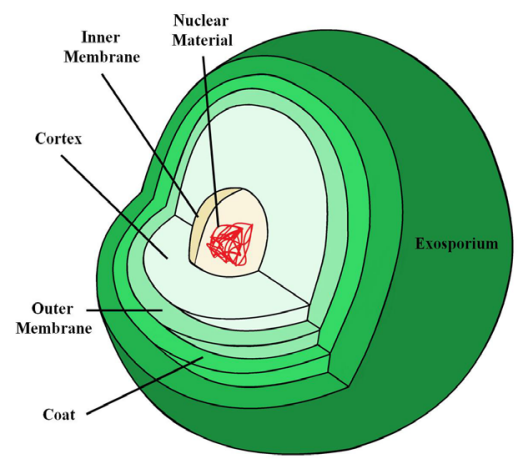

Figure 2: Bacterial spore structure. From the inner to the outer: a) nuclear material and b) inner membrane constitute the core of the spore; c) cortex protect the spore from high temperature and maintain the core in a dehydrated state; an d) outer membrane divide the cortex from the e) protein coat, which is involved in germination and in conferring spore resistance to heat and chemical agents. Exosporium, a facultative external structure present only in some bacterial spores, plays a role in the protection of the spore and in its environmental interactions.

vegetative form of $B$. subtilis is actually considered as a good simulant of such bacteria. Like B. anthracis, this microorganism is Gram-positive, rod-shaped and may forms a protective endospore, which allows him to survive in extreme environmental conditions. No risks for laboratory personnel have been identified from the use of B. subtilis. Moreover, since it is a naturally-occurring bacterium, release of its spores in the air will not cause any environmental impact.

\section{Bacterial spore BWA and BWA-S}

The ability of some bacteria to form spores, has allowed an adaptation to survive in extreme conditions. Typical Gram-positive originated spores share a common organization, consisting of three substructures: the core, the cortex and the coat (Figure 2). The core is located at the centre of the spore, and harbours DNA and small acid soluble proteins. The cortex is a layer of peptidoglycan, which plays a role in maintaining the core in a dehydrated state. In addition, this structure is essential to protect the spore from high temperature. Externally, spores are protected by a morphologically complex protein coat, which has been considered important in germination and in conferring spore resistance to heat and chemical agents [25]. In some species, such as $B$. subtilis, the coat represents the outermost detectable layer of spores, whereas other Bacillus species, like $B$. anthracis and $B$. thuringiensis show an additional external structure, called exosporium [26], which plays a role in protection of the spore and in its environmental interactions [27]. The spores could be spread into powders, sprays, food, and water [2,28], without being perceived by human senses. When the spore encounters nutrients (e.g. into the human body), it breaks dormancy and turns them into active growing cell. In this way, the bacteria can multiply themselves, producing toxins and causing severe diseases and death if it is pathogen [29].

Spores of non-pathogenic Bacillus species can be used as simulants of $B$. anthracis spores in pursuing counter strategies [26], avoiding unnecessary exposure to pathogens and potential risks for health of researchers [30]. B. anthracis is considered a major potential biological threat as bioweapon [31-33]; it is a Gram-positive, rod shaped bacterium. Its virulence and lethality is determined by two important factors: the presence of an anti-phagocytic polysaccharide capsule that allows it to escape host's immune response, and the production of the anthrax toxin, mainly cytotoxic to macrophages [34]. B. anthracis 
may persist in the environment for many years, due to its aptitude to form spores. In fact, whereas vegetative Bacillus cells do not survive in adverse environmental conditions, the spores are resistant to chemical agents, drying, temperature variations, pressure, extreme $\mathrm{pH}$, radiations $[5,32,35,36]$ and high vacuum, allowing $B$. anthracis to survive for decades and perhaps much longer [8]. Because of their strong resistance, as well as the easy availability in nature or production in a microbiology laboratory, $B$. anthracis spores are easily suitable to be used as biological weapons [29].

B. atrophaeus subsp. globigii, closely related to B. subtilis but phylogenetically distinct from it, has been used for many years as a simulant of $B$. anthracis. It was one of the bacteria used during the "Project 112" (1962-1973) by USA army as a simulant of anthrax. However, following studies have shown that, B. atrophaeus subsp. globigii shares many features with $B$. anthracis, for example a similar morphology of vegetative cells. Nevertheless, it shows different thermal properties [26], which decrease its utility as a simulant for $B$. anthracis. Due to these limitations, several research groups assessed the suitability of another simulant for B. anthracis: Bacillus thuringiensis, a spore-forming bacterium living in the soil. In nature, once ingested, it releases the $\delta$-endotoxin (or Cry protein) which is harmless for human health but widely implied in insecticidal activities, by damaging cell membranes of target organisms, and, consequently, leading to cell lysis and eventually to cell death. Its similarities with both vegetative cells and spores of B. anthracis, make this bacterium a good simulant of such pathogen.

\section{Protein Toxin BWA and BWA-S}

Several diseases, mainly bacterial, are toxins mediated. Although toxins are considered biological agents, they are not living organisms, but small molecules produced by them [2], and secreted outside the cell (exotoxins, of protein nature) or closely connected to it (endotoxins, or lipopolysaccharidic toxins). For this reason, conversely to other biological agents, toxins cannot multiply in a host organism and harm solely the population exposed [31]. In diseases caused by toxigenic bacterial species, toxins play a key role and strains unable to produce them are avirulent. Besides bacteria, many other organisms like, animals, plants and fungi, are able to produce toxins; one of particular interest in the field of bioweapons is ricin, extracted by Ricinus communis. Toxins can be compared to poisonous substances. When they penetrate in a host, they cause a disease also without a vector (bacteria or other living organism). For this reason, toxins as ricin, botulinum toxin, or staphylococcal enterotoxins can represent a very dangerous threat, and in some cases even a small amount of molecule can be lethal.

Among the more hazardous toxins for humans, the one produced by C. botulinum bacterial strains includes the most powerful poison known so far. At present, seven different bacterial strains are recognized as toxin producer; they synthesize seven serologically distinct neurotropic toxins, designated by the letters A through $G$ [37]. Each strain produces only one kind of toxin. The most relevant types for human health are A (Figure 3), B, E, and F, whereas G is rare and occasionally described in humans. $\mathrm{C}$ and $\mathrm{D}$ are the most toxic for animals [38]. All forms of botulism may be fatal and are considered medical emergencies [39], which require immediate intervention to prevent additional cases in order to limit its impact on public health. Mortality is proportional to the amount of toxin ingested or inhaled, and consistent with toxins affinity towards nervous tissue, which decreases from $\mathrm{A}$ to $\mathrm{E}$ and to $\mathrm{B}$. Once dispersed, a single gram of crystalline botulism neurotoxin would kill more than 1 million people,

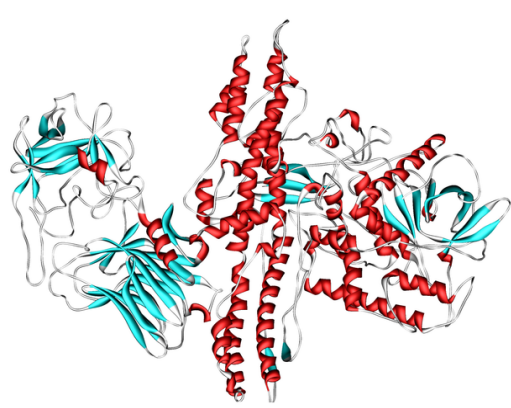

Figure 3: Clostridium botulinum toxin, type A. In red $\alpha$-helix and in light blue $\beta$-sheets secondary protein organization is shown. (PDB 3BTA) [46].
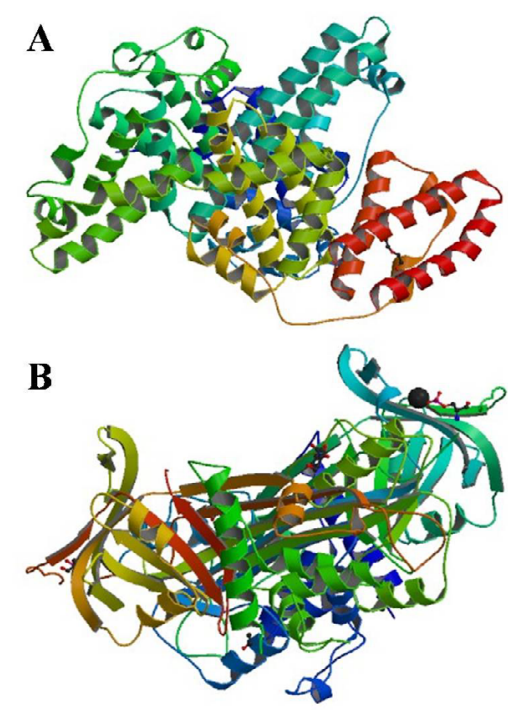

Figure 4: Bovin Serum Albumin (A) and Ovalbumin (B). $\alpha$-helix and $\beta$-sheets secondary protein organization are shown. (A, PDB 3V03) [47]; B, PDB 1OVA [48].

owing to inhalation [40]. Development and use of C. botulinum toxin as bioweapon started at least 70 years ago [41]. The Japanese biological warfare group, Unit 731, formally intended for water purification, was committed to studying and testing chemical and biological weapons, thus violating the Geneva Protocol, which Japan subscribed in 1925. General Ishii Shiro, expert bacteriologist and head of the group, admitted to administering cultures di C. botulinum to prisoners with lethal effect during the occupation of Manchuria, which began in the 1930s. These practices had a dual purpose: the experimentation of bioweapons to be used against enemies, and testing new therapeutic strategies on prisoners exposed to contagion in order to cure sick and wounded Japanese soldiers in a more effective way [42].

More recent events involving C. botulinum toxin use lead us in 1990s, after the Persian Gulf War, when Iraq admitted to an UN inspection group to having produced 19000 liters of concentrated toxin A, and loaded almost an half of which into military weapons $[43,44]$. The total amount of botulin produced constitutes approximately 3 times that needed to kill the whole human population by inhalation [40].

To study the release of protein toxins and adequate detection systems, Bovine Serum Albumin (Figure 4A) and Ovalbumin 
(Figure 4B), which show the same aminoacids acting as endogenous fluorophores, are considered suitable simulants that let operators work in safety conditions [45] and that would be useful in bioterrorist attack response for recognizing the real BWA distinguishing it from the environmental background.

\section{Conclusions}

Letters with anthrax sent by post to press and government personalities demonstrated that biological threat had become a reality which countries had to come to terms with. Although sporadic, the intentional use of biological agents with offensive purposes gives rise to general concern, resulting in an impact that goes beyond the number of casualties. Scientific and technological progress, have led to the construction of innovative and ever more sophisticated tools, bioterrorism attacks may be likely more effective than in the past. Great attention must be paid towards relatively unknown pathogens, and those emerging from bioengineering manipulation and modern molecular biology techniques [1]. For biodefence, it is crucial to develop and to improve new detection technologies. In order to develop standoff detection systems, it is essential to implement the training of neural networks through the use of simulants that reflect real BWA.

The perfect simulant, suitable for the training of neural networks, should be morphologically similar to the BWA, sharing size, shape and inner structures, such as natural fluorophores and, finally its suitability requires non-hazardousness [30].

\section{Acknowledgement}

Special acknowledgments for the realization of this work go the International Master Courses in "Protection against CBRNe events". (www.mastercbrn.com).

\section{References}

1. Jansen HJ, Breeveld FJ, Stijnis C, Grobusch MP (2014) Biological warfare bioterrorism, and biocrime. Clin Microbiol Infect 20: 488-496.

2. Katz R (2004) Biological weapons: a national security problem that requires a public health response. OPR Working Paper Series, Princeton University, Princeton, NJ, USA.

3. Carestia M, Pizzoferrato R, Cenciarelli O, D'Amico F, Malizia A, et al. (2014) Fluorescence measurements for the identification of biological agents feature for the construction of a spectra database. In Photonics Technologies, 2014 Fotonica AEIT Italian Conference, 1-4

4. Cenciarelli O, Rea S, Carestia M, D’Amico F, Malizia A, et al. (2013a) Bioweapons and Bioterrorism: A Review of History and Biological Agents. Defence S\&T Tech Bull 6: 111-129.

5. Mclntosh AJ, Barrington SJ, Bird H, Hurst D, Spencer P, et al. (2012) Spectroscopic analysis of bacterial biological warfare simulants and the effects of environmental conditioning on a bacterial spectrum. Anal Bioanal Chem 404 2307-2315.

6. Cenciarelli O, Malizia A, Marinelli M, Pietropaoli S, Gallo R, et al. (2013b) Evaluation of biohazard management of the Italian National Fire Brigade. Defence S\&T Tech Bull 6: 33-41.

7. Malizia A, Quaranta R, Mugavero R (2010) CBRN events in the subway system of Rome: Technical-managerial solutions for risk reduction. Defence S\&T Tech Bull 3: 140-157.

8. Joshi D, Kumar D, Maini AK, Sharma RC (2013) Detection of biological warfare agents using ultra violet-laser induced fluorescence LIDAR. Spectrochim Acta A Mol Biomol Spectrosc 112: 446-456

9. Pazienza M, Britti MS, Carestia M, Cenciarelli O, D'Amico F, et al. (2013) Application of real-time PCR to identify residual bio-decontamination of confined environments after hydrogen peroxide vaportreatment: Preliminary results. J Microb Biochem Technol 6: 24-28.

10. Pazienza M, Britti MS, Carestia M, Cenciarelli O, D'Amico F, et al. (2014) Use of Particle Counter System for the Optimization of Sampling, Identification and Decontamination Procedures for Biological Aerosols Dispersion in Confined Environment. J Microb Biochem Technol 6: 043-048.
11. Malizia A, Quaranta R, Mugavero R, Carcano R, Franceschi G (2011) Proposal of the prototype RoSyD-CBRN, a robotic system for remote detection of CBRN agents. Defence S\&T Tech Bull 4: 64-76.

12. Cenciarelli O, Pietropaoli S, Frusteri L, Malizia A, Carestia M, et al. (2014) Biological Emergency Management: The Case of Ebola 2014 and the Air Transportation Involvement. J Microb Biochem Technol 6: 247-253.

13. Tucker JB (2000) Motivations For and Against Proliferation: The Case of the Middle East. Biological Warfare: Modern Offense and Defense 27-52.

14. Alibek K, Handelman S (1999) Biohazard: The Chilling True Story of the Largest Covert Biological Weapons Program in the World-Told from Inside by the Man Who Ran It. Random House, New York, USA.

15. US Army (1999) Biological defense operations, Corps/Company tactics, techniques and procedures. Field Manual 30101-06.

16. Utgoff VA (1993) The biotechnology revolution and its potential military implications. Biological weapons: Weapons of the future. In: Roberts and Browder. Biological Weapons: Weapons of the Future? Center for Strategic and International Studies. Washington DC, USA

17. Carus SW (1991) The Poor Man's Atomic Bomb? Biological Weapons in the Middle East. The Washington Institute for Near East Policy. Policy Papers Number 23. Washington DC, USA.

18. Finnegan W (2001) The poison keeper. The New Yorker 15: 45-78.

19. Dennis C (2001) The bugs of war. Nature 411: 232-235.

20. Centers for Diseases Control and Prevention (CDC). (2014) Bioterrorism Agents/Diseases.

21. La Placa M (2012) Principles of Medical Microbiology. Società Editrice Esculapio, Bologna, Italy. [in Italian]

22. Perry RD, Fetherston JD (1997) Yersinia pestis--etiologic agent of plague. Clin Microbiol Rev 10: 35-66.

23. Starr MP (1981) The genus Erwinia. The prokaryotes. A handbbook of habitats, isolation and identification of bacteria. Springer-Verlag, Berlin, Germany, pp. 1261-1271.

24. Costa E, Teixidó N, Usall J, Fons E, Gimeno V, et al. (2002) Survival of Pantoea agglomerans strain CPA-2 in a spray-drying process. J Food Prot 65: 185-191.

25. Giorno R, Bozue J, Cote C, Wenzel T, Moody KS, et al. (2007) Morphogenesis of the Bacillus anthracis spore. J Bacteriol 189: 691-705

26. Carrera M, Zandomeni RO, Fitzgibbon J, Sagripanti JL (2007) Difference between the spore sizes of Bacillus anthracis and other Bacillus species. J Appl Microbiol 102: 303-312.

27. Henriques AO, Moran CP Jr (2007) Structure, assembly, and function of the spore surface layers. Annu Rev Microbiol 61: 555-588.

28. Zilinskas R (1999) Assessing the threat of Bioterrorism. Congressional Testimony to subcommittee on national security, Veteran's Affairs and International Relations, US House of Representatives, USA.

29. Mehta P, Antao V, Kaye W, Sanchez M, Williamson D, et al. (2014) Prevalence of amyotrophic lateral sclerosis-United States, 2010-2011. MMWR Surveill Summ 63 Suppl 7: 1-14.

30. Farrell S, Halsall HB, Heineman WR (2005) Bacillus globigii bugbeads: a mode simulant of a bacterial spore. Anal Chem 77: 549-555.

31. Klietmann WF, Ruoff KL (2001) Bioterrorism: implications for the clinical microbiologist. Clin Microbiol Rev 14: 364-381.

32. Arakawa ET, Lavrik NV, Datskos PG (2003) Detection of anthrax simulants with microcalorimetric spectroscopy: Bacillus subtilis and Bacillus cereus spores. Appl Opt 42: 1757-1762.

33. Bush LM, Abrams BH, Beall A, Johnson CC (2001) Index case of fatal inhalational anthrax due to bioterrorism in the United States. N Engl J Med 345: 1607-1610.

34. Abrami L, Reig N, van der Goot FG (2005) Anthrax toxin: the long and winding road that leads to the kill. Trends Microbiol 13: 72-78.

35. Dragon DC, Rennie RP (1995) The ecology of anthrax spores: tough but not invincible. Can Vet J 36: 295-301.

36. Munakata N, Hieda K, Kobayashi K, Ito A, Ito T (1986) Action spectra in 
Citation: Cenciarelli O, Pietropaoli S, Gabbarini V, Carestia M, D’Amico F, et al. (2014) Use of Non-Pathogenic Biological Agents as Biological Warfare Simulants for the Development of a Stand-Off Detection System. J Microb Biochem Technol 6: 375-380. doi:10.4172/1948-5948.1000172

ultraviolet wavelengths $(150-250 \mathrm{~nm})$ for inactivation and mutagenesis of Bacillus subtilis spores obtained with synchrotron radiation. Photochem Photobiol 44: 385-390.

37. Mehta P, Antao V, Kaye W, Sanchez M, Williamson D, et al. (2014) Prevalence of amyotrophic lateral sclerosis - United States, 2010-2011. MMWR Surveill Summ 63 Suppl 7: 1-14.

38. Montecucco C (1995) Clostridial neurotoxins: the molecular pathogenesis of tetanus and botulism. Springer, Berlin, Germany.

39. Mehta P, Antao V, Kaye W, Sanchez M, Williamson D, et al. (2014) Prevalence of amyotrophic lateral sclerosis - United States, 2010-2011. MMWR Surveill Summ 63 Suppl 7: 1-14.

40. Arnon SS, Schechter R, Inglesby TV, Henderson DA, Bartlett JG, et al. (2001) Botulinum toxin as a biological weapon: medical and public health management. JAMA 285: 1059-1070.

41. Smart JK (1997). History of chemical and biological warfare: an American perspective. Medical Aspects of Chemical and Biological Warfare. Washington, DC: Office of the Surgeon General 9-86.
42. Shukla HD, Sharma SK (2005) Clostridium botulinum: a bug with beauty and weapon. Crit Rev Microbiol 31: 11-18.

43. Cohen J, Marshall E (2001) Bioterrorism. Vaccines for biodefense: a system in distress. Science 294: 498-501.

44. Zilinskas RA (1997) Iraq's biological weapons. The past as future? JAMA 278: 418-424.

45. Sivaprakasam V, Huston A, Scotto C, Eversole J (2004) Multiple UV wavelength excitation and fluorescence of bioaerosols. Opt Express 12: 4457-4466.

46. Lacy DB, Tepp W, Cohen AC, DasGupta BR, Stevens RC (1998) Crystal structure of botulinum neurotoxin type $A$ and implications for toxicity. Nat Struct Biol 5: 898-902.

47. Majorek KA, Porebski PJ, Dayal A, Zimmerman MD, Jablonska K, et al. (2012) Structural and immunologic characterization of bovine, horse, and rabbit serum albumins. Mol Immunol 52: 174-182.

48. Stein PE, Leslie AG, Finch JT, Carrell RW (1991) Crystal structure of uncleaved ovalbumin at $1.95 \mathrm{~A}$ resolution. J Mol Biol 221: 941-959. 